\title{
ISO 9000 Certification: A First Step to Improve Supply Chain Performance, Evidence from Pakistan
}

\author{
Saeed AMER \\ School of Management \\ Wuhan University of Technology \\ Wuhan, P.R. China, 430070 \\ School of Business and Economics \\ University of Management and Technology (UMT) \\ Lahore, Pakistan, 54000 \\ amersaeed@whut.edu.cn, amer.saeed@umt.edu.pk
}

\author{
M. Prasad F. JAYASURIYA \\ School of Management \\ Wuhan University of Technology \\ Wuhan, P.R. China, 430070 \\ mprasadfj@yahoo.com
}

\begin{abstract}
Supply chain management has become a strategic tool to gain competitive advantage in today's global market. To survive and prosper in this sort of competition supply chains continuously need to check and improve their performance. Small and medium enterprises (SME's), especially in developing countries are under high pressure to improve. This study is an attempt to provide guidance to top management of SME's to focus on getting a basic level QMS certification like ISO 9000. It can be a good starting point to improve its performance and ultimately become an active partner for improved performance of the whole supply chain. A survey based research was conducted and performance of ISO certified and non-certified SME's in Pakistan was compared. Results clearly indicate that companies with ISO certification have higher supply chain performance in comparison of non-certified companies.
\end{abstract}

Keywords-ISO 9000; Supply chain performance; SME's; Developing countries; Pakistan

\section{INTRODUCTION}

Considering the world as a global village is not a dream now, rather it has become a reality. Today's business world is highly dynamic and facing the challenges of very tough competition, not only on the variety of products but also on quality, cost and availability of the products to maximize the customer service level [1]. Supply chain management (SCM) is one of the answers of such tough competitive situations along with collaboration of quality management systems (QMS). A lot of research is being done to integrate SCM and QMS like ISO 9000 or TQM practices to improve overall quality and efficiency of supply chains in minimum possible time and cost [2]. A continuous performance evaluation system is necessary to maintain a higher customer satisfaction level. Unfortunately so far there is no consensus on supply chain performance measurement method, mechanism, framework, level of analysis, dimension, timings or how and when revision of these measurement methods should be done [3-7]. There are many facets of supply chain performance measurement research that includes a discussion on whether it should be quantitative or qualitative, cost based indicators or non-cost based, efficiency based including speed, flexibility and higher customer service level and either it should be only strategic level or tactical and operational level measurement should also be part of this measurement system [4, 5, 8].
Companies in developing countries like Pakistan have not many resources to experiment different ideas to fulfill the requirements of their customers in developed countries. They need to find out clearly identifiable and calculable performance indicators or systems which can guide them to prosper. Previous research shows that implementing a basic level QMS like ISO 9000 could be a starting point to improve overall performance of not only the focal company but ultimately the whole supply chain.

Based upon above discussion this study is an attempt to find out the answer of following research question.

- Do ISO 9000 certified companies perform better as compare to non ISO 9000 certified companies?

The paper is organized in five sections. First section presents the introduction, research question and relative importance of the study. Second section presents detailed literature review on supply chain performance and a description of all nine performance indicators. Third section presents results of statistical analysis while fourth section gives the conclusion. Limitations of the study and future research directions are presented in fifth section.

\section{LITERATURE REVIEW}

\section{A. Supply Chain Performance}

Performance is the set of actions performed to achieve a predefined set of goals. When these goals are related to functioning of supply chain then it would be called as supply chain performance. Supply chain performance is dependent upon the integrated role of all the stages of a supply chain from acquiring raw materials to converting them into a finished product and delivered to the end customer[9]. Supply chain performance is dependent upon how much a supply chain is fulfilling the requirements of the customers and at which total cost [6]. To improve the overall supply chain efficiency and effectiveness the most important first step is to improve the business performance of the focal firm and then move towards the overall supply chain. $[3,5]$.

There are many SCM performance frameworks trying to identify and measure different aspects of a supply chain, but still there is no common agreed upon SCM performance framework. The most commonly used frameworks are based upon cost and/ or customer responsiveness. Following are some of the most cited frameworks for supply chain performance. Flexibility in the systems and resource 
performance are the factors identified and measured by [10] and followed by [11]. SCOR model is developed by supply chain council including plan, source, make, deliver and return phases of a whole supply chain. Cost containment and performance reliability are the main indicators in the framework developed by [12] in which cost of inbound and outbound activities, inventory holding costs comes under cost containment while order fulfillment rate, safety stocks, inventory obsolescence and number of product warranty claims are discussed in reliability construct.

But there are certain issues creating hurdles in the adoption of any of them as an industry standard to measure supply chain performance. Either they should be focusing on any one or two areas and most importantly they require a lot of information to be shared by all the partners which need not only high level of trust but also incur huge costs, time and efforts of dedicated people or departments [5]. High cost and time requirements and technical expertise needed to measure supply chain performance through all these frameworks make it impossible for SME's to even think about them [3]. Then in Asian countries like Pakistan where companies have very little trust on each other it is very difficult to share true information [13], and about the whole processes it would be even difficult if not impossible to measure the whole supply chain performance.

\section{B. Performance Indicators}

Following are the performance indicators used in this study.

\section{1) Product Quality $(P Q)$}

Product quality is defined in many ways by the quality gurus and it has added many dimensions with the passage of time. According to an upgraded definition by [14] quality is "fitness for purpose". Product quality is defined in a more comprehensive way by [15] in stating that it is "the combination of any product's engineering characteristics and manufacturing that will determine how much expectations of the customers are fulfilled by the product in use". Product quality is the definite indicator of performance of any organization and the whole supply chain as product is the thing for which whole supply chain is working and the end customer is paying for [16].

\section{2) Waste Level (WL)}

Anything that doesn't create value during product development process is a waste of time, money and energy. Waste can arise almost at every stage and step of the supply chain. Some waste created within the boundary of a company while others can emerge from the product flows between different supply chain partners [17]. Waste in any shape has not only its financial cost but it is also in the shape of loss to the environment as it losses of all the embedded carbon and water resources $[17,18]$.

3) Reliability $(R B)$

It is one of the key features all supply chain partners seeking now a day from other partners. It is also linked to different levels and positions of the whole supply chain process. It is part of product quality with respect to conformance, as it shows how much a product is in accordance to its specifications [16]. It is also key variable while selecting a supplier as getting inventory on time and in full amount is one of the key ingredients of success in today's time competitive environment.

\section{4) Return on Assets (RoA)}

ROA is applied to measure the efficiency of a company in using its assets in generating net income. It is a ratio of annual net income to average total assets of a company during a financial year. It is a very useful indicator to find out and gauge the competitive performance of any organization keeping in view that it is an industry specific measure and can be used to compare companies of the same industry[19].

\section{5) Productivity $(P R)$}

It is the simplest efficiency measure of a production facility and represented by the ratio of output generated to inputs involved in a production process. It is an important performance measure under operational performance of a supply chain [19].

\section{6) Durability $(D B)$}

It is the ability to be in working condition without decrease in quality for a longer period of time. It is one of the product based quality dimension. Durable materials and products are necessary and required to be used as they help environment through conserving materials [18]. Companies offering durable products get advantage through quality, environment friendly and cost effective products. In this way it's an important area to measure representing both quality and company performance.

\section{7) Sales Growth ( $S G)$}

It is simply increase in total sales of a company in a specific period of time. Businesses are there in the market to offer their products to customers, taking market share through collaboration and forming supply chains to earn profits. Supply chain performance measurement has different aspects, some of them are hard, while some are soft areas. Sales growth is one of the areas which can be easily calculated and measured and clearly tells the outcome of all the efforts made in different areas of the organization and the supply chain to fulfill the needs of a customer, and increase in sales could be a good indicator of customer satisfaction [6].

\section{8) Cycle Time (CT)}

It is the end-to-end delay in a business process. The business processes are the supply chain process and the order-to-delivery process. Cycle time can be divided in two categories. One is order to delivery and the second one could be supply chain cycle time. First one represents the time passed from placing an order by the customer to order delivered to the customer [20]. The supply chain cycle time is the sum of all the times required by the suppliers, manufacturer, distribution and logistics related activities to convert raw materials into finished goods and to deliver the products to the end customer. It is very important performance indicator because of the time based competition between supply chains now a day and can affect the customer service level badly.

\section{9) Regularity $(R G)$}

It shows the capability of a company or a supply chain for meeting the demands for on time deliveries or performance. It can include that how consistently a company produces its products without delays and deliver 
on time and in full [4]. This is also a very important area to take care of for enhanced customer service levels.

Based upon above explanation of supply chain performance and its indicators, following hypothesis has been formed by the current study.

Hypothesis: Performance of ISO 9000 certified companies in a supply chain is higher than non ISO 9000 certified companies.

\section{ANALYSIS}

Unit of analysis in the current study includes manufacturing sector SME's of Pakistan. Sampling frame for this study consists of chamber of commerce and industries of cities of Lahore, Faisalabad and Sialkot from Pakistan. Sample includes both ISO 9000 certified and noncertified companies so that a comparison can be made. Respondents for this study are CEO's, supply chain managers, quality managers and production managers. Questionnaires were mailed to 485 companies and a total of 126 responses were received out of which 114 were found valid for analysis. These responses contain 64 ISO certified and 50 non-ISO certified companies.
This study has used a part of survey questionnaire of [21] which taken proxy variables to collect performance data. It was modified a little according to the needs of the study. The survey instrument asked from the respondents to rank themselves against their competitors based on 9 performance indicators described earlier. All the questions have five points likert scale where (1 Much worse than the competitors: 5 Much better than the competitors). The questionnaire also includes questions related to general \& demographic information of the respondent.

SPSS 20 is used to analyze the data. First of all Cronbach alpha test is used on the pilot sample to check the internal consistency of the instrument. According to Bryman [22] the reliability range is one to zero and values fall within 0.6 to 0.8 are acceptable. The alpha value for performance indicators for pilot sample was 0.782 which is within acceptable range. To test the defined hypothesis current study has used nine performance indicators and at first step mean score of every indicator was calculated. After that a mean score of all performance indicators was calculated for every company.

TABLE I. PERFORMANCE INDICATORS MEAN SCORES

\begin{tabular}{|c|c|c|c|c|c|c|c|c|}
\hline Indicators & PQ & WL & RB & ROA & PR & DB & SG & CT \\
\hline ISO & 4.2 & 3.6 & 4.0 & 3.5 & 4.0 & 4.0 & 4.4 \\
\hline Non ISO & 3.8 & 2.8 & 3.9 & 3.0 & 3.5 & 3.6 & 3.0 \\
\hline
\end{tabular}

Finally by using every company mean score the mean of means was calculated for all ISO certified and non-certified companies. These two values were compared with the help of independent sample t-test. When the samples are independent and population standard deviation is unknown

the ' $\mathrm{t}$ ' statistic can be used to test the hypothesis for difference between two population means [22]. Result of ttest proved the hypothesis that performance of ISO certified companies is better than the non-certified companies in Pakistan.

TABLE II. Independent sample t-test results

\begin{tabular}{|c|c|c|c|c|c|c|c|}
\hline \multirow{2}{*}{ Field } & \multicolumn{2}{|c|}{ Mean } & \multicolumn{2}{|c|}{ Std. Dev } & \multirow{2}{*}{ Levine's Test Sig } & \multirow{2}{*}{$t$} & $\boldsymbol{p}$ value \\
\cline { 2 - 7 } & ISO & N-ISO & ISO & N-ISO & & -7.168 & .000 \\
\hline \multirow{2}{*}{ Performance } & 3.938 & 3.442 & .4192 & .2848 & .114 & -148 \\
\hline
\end{tabular}

The assumption for independent sample t-test is that equal variance should be assumed across groups and cases. For this we usually make use of Levine's test. If the significance value of Levine's test is $>0.05$ then assumption of equal variance is being met. This field assumes equality of variance as its significance value for Levine's test is .787 which is higher than required .05 . There was a significant difference in the scores for ISO certified $(\mathrm{M}=3.938$, $\mathrm{SD}=.4192)$ and non-certified $(\mathrm{M}=3.442, \mathrm{SD}=.2848)$ conditions; $\mathrm{t}(112)=-7.168, \mathrm{p}=.000$. This result shows that the difference between the means of two conditions is not by chance and it really exists.

\section{CONCLUSION}

QM practices are an effort to improve organizational performance continuously while supply chain management is trying to create seamless processes in entire supply chain. It shows that both are interlinked and improvement in one positively affects the other. The hypothesis of this study is that companies with ISO certification have higher performance as compare to non-certified companies. As discussed earlier this study has adopted an instrument by
[21] which has nine performance indicators covering cost, time and flexibility dimensions of supply chain performance aiming for high quality products with higher customer satisfaction level. These are also such indicators which can be easily calculated and measured by any size of a company and many companies would not find it difficult to share such information. The quantitative analysis results prove that companies with ISO certification have higher performance on all nine indicators individually and collectively. It gives a clear indication to management of all those companies in the developing world who wants to be an active member in overall improvement of supply chain performance in a minimum possible time, at lower cost and minimizing the overall risk of change that they should adopt a QMS like ISO 9000 at first with its true spirit and that will guide and lead them to higher performance levels.

\section{LIMITATIONS AND FUTURE RESEARCH}

This research has been done in a single country Pakistan with a basic level cross sectional data with majority of the participating firms are SME's. So, at this time it's not generalizable to all kind of companies and with very 
complicated environments. In future a longitudinal research with different levels of companies and in different parts of the world can be conducted to make results more generalizable.

\section{REFERENCES}

[1]. Avelar-Sosa, L., et al.,"Impact of traditional and international logistic policies in supply chain performance", The International Journal of Advanced Manufacturing Technology, vol. 76, pp. 913925, May-Aug. 2015.

[2]. El Mokadem, M., "ISO 9000 moderation role over supply chain alignment in manufacturing context", Journal of Manufacturing Technology Management,vol. 27, pp. 338-363,Mar. 2016.

[3]. Banomyong, R. and N. Supatn, "Developing a supply chain performance tool for SMEs in Thailand", Supply Chain Management: An International Journal,vol.16, pp. 20-31, Jan. 2011

[4]. Gunasekaran, A. and B. Kobu, "Performance measures and metrics in logistics and supply chain management: a review of recent literature (1995-2004) for research and applications", International Journal of Production Research,vol. 45, pp. 2819-2840, Dec. 2007.

[5]. Shepherd, C. and H. Günter, "Measuring supply chain performance: current research and future directions", International Journal of Productivity and Performance Management,vol.55, p p. 242-258, Mar.-Apr., 2006.

[6]. Arzu Akyuz, G. and T. Erman Erkan, "Supply chain performance measurement: a literature review", International Journal of Production Research,vol.48, pp. 5137-5155, 2010.

[7]. Flynn, B.B., B. Huo, and X. Zhao, The impact of supply chain integration on performance: a contingency and configuration approach. Journal of Operations Management,vol. 28, pp. 58-71, Jan. 2010.

[8]. Bhagwat, R. and M.K. Sharma, "Performance measurement of supply chain management: A balanced scorecard approach. Computers \& Industrial Engineering",vol.53, pp. 43-62, Jan. 2007.

[9]. Taticchi, P., et al., "A review of decision-support tools and performance measurement and sustainable supply chain management", International Journal of Production Research, vol.53, pp. 6473-6494, 2015.

[10]. Beamon, B.M., "Measuring supply chain performance", International Journal of Operations \& Production Management, vol. 19, pp. 275-292, Mar. 1999.
[11]. Sezen, B., "Relative effects of design, integration and information sharing on supply chain performance", Supply Chain Management: An International Journal, vol.13,pp. 233-240, Mar. 2008.

[12]. Lee, C.W., I.-W.G. Kwon, and D. Severance, "Relationship between supply chain performance and degree of linkage among supplier, internal integration, and customer", Supply Chain Management: An International Journal,vol.12, pp. 444-452,Jun. 2007.

[13]. Kureshi, N., F. Qureshi, and A. Sajid, "Current health of quality management practices in service sector SME: A case study of Pakistan", The TQM Journal,vol.22, pp. 317-329,Mar. 2010.

[14]. Defeo, J. and J.M. Juran, Juran's Quality Handbook, The Complete Guide to Performance Excellence 6/e, McGraw Hill Professional, 2010.

[15]. Feigenbaum, A.V., Total quality control: achieving productivity, market penetration and advantage in the global economy, McGrawHill Higher Education, 2005.

[16]. Lotfi, Z., et al., "The Relationships between Supply Chain Integration and Product Quality", Procedia Technology,pp. 471-478, Nov. 2013.

[17]. WRAP, Supply Chain manage and measure waste WRAP: London. pp. 20, 2012.

[18]. Azevedo, S.G., H. Carvalho, and V. Cruz Machado, "The influence of green practices on supply chain performance: a case study approach", Transportation Research Part E: Logistics and Transportation Review,vol 47, pp. 850-871, June 2011.

[19]. Fawcett, S.E., et al., "Information sharing and supply chain performance: the role of connectivity and willingness", Supply Chain Management: An International Journal, vol.12, pp. 358-368, May 2007.

[20]. Chopra, S. and P. Meindl, Supply chain management. Strategy, planning \& operation. Springer, 2007.

[21]. Lakhal, L., F. Pasin, and M. Limam, Quality management practices and their impact on performance. International Journal of Quality \& Reliability Management,vol23, pp. 625-646, June 2006.

[22]. Bryman, A. and E. Bell, Business research methods. Oxford university press, 2007. 